\title{
Marie-Odile Marion Entre anhelos y recuerdos, México, editorial Plaza y Valdés/UNICACH,
}

175 pp., 1997

En el libro titulado Entre anhelos y recuerdos, de Marie Odile Marion, antropóloga de sólida presencia y prestigio bien ganado, quien falleció el 17 de junio de 1999, se rescatan los testimonios directos de seis mujeres lacandonas y revela, por la frescura y espontaneidad de sus datos, un mundo poco conocido. La autora, gracias a la gran experiencia y al conocimiento profundo sobre las comunidades indígenas, ubica en su contexto los pasajes de vida que ella recopiló a través de varias temporadas de campo y luego tradujo, permitiéndonos penetrar en esferas $y$ en medios sociales inaccesibles por otra vía, ya que deja que el actor social pueda hablar de su propia experiencia. Las mujeres transmiten los hechos relevantes que se mantienen vivos en su memoria, y sólo por este proceso es posible aprehender una sociedad desde adentro.

Los textos de tradición oral son de gran valor para el enriquecimiento de la antropología; reflejan un proceso cultural dinámico, constituyen un sistema complejo de información, de comunicación cultural y de representaciones de grupo. La autora nos presenta un material etnohistórico de primera mano, sujeto a la crítica, al análisis $\mathrm{y}$ a posteriores interpretaciones; las narraciones contenidas en el libro, muestran la experiencia comunitaria del grupo lacandón, su práctica social y normas, sus valores, lo que constituye su patrimonio cultural; en un sentido amplio podemos observar qué es lo importante en dicha sociedad, qué intentan sus miembros enseñar, preservar, defender y modificar.

En la breve pero rica presentación de los textos, Marie Odile Marion transmite la identidad cultural de la comunidad lacandona y refiere el controvertido proceso de inserción o rechazo en la sociedad de los dzules; primero penetran chicleros y madereros que llevan violencia, corrupción y enfermedades desconocidas para los lacandones como el sarampión y la gripa, que causan verdaderas epidemias y mortandad; más tarde llegan evangelizadores que modifican, entre otras costumbres, los patrones matrimoniales y con ello se fractura el equilibrio social; también hacen su aparición turistas y xateros que provocan otros tipos de contacto, no por ello menos nefastos. No podían faltar hombres sin escrúpulos que utilizan a los lacandones y que no muestran ningún reparo al robar a las mujeres o asesinar a familias enteras para el logro de sus fines. Los textos indígenas reflejan las decepciones ante el mundo occidental que no comprende ni respeta otra realidad.

La espontaneidad y originalidad de cada uno de los textos nos permite conocer, por boca propia de los lacandones, su percepción sobre la selva, los ríos que la surcan como el Lacanjá, el Cedro, lagos como el Carranza o el Noh Pethá y la laguna Jalisco. Se refieren a los animales que cazan los miembros masculinos de la comunidad como el faisán, el jabali, el tepezcuintle, el saraguato y el tapir, o bien a otros recursos naturales con los que las mujeres proveen a la familia y complementan su alimentación, como los peces y otros producto de la recolección como los huevos de iguana, lagarto y de tortuga, al igual que la miel que guardan en calabazas. También se mencionan los recursos que emplean para otros fines como la majahua para hacer hamacas, o bien plantas medicinales para "matar el vene- 
no" de una víbora. Aluden a otros cultivos propios de ese medio ambiente como la piña, la papaya, el plátano, la ciruela, la yuca, el algodón para hilar sus túnicas y el tabaco. Asimismo, se angustian por la destrucción de su hábitat, por obra principalmente de madereros y colonos de otras regiones, que paso a paso devoran a la selva que es la que permite su protección y, en última instancia, su sobrevivencia.

Las mujeres cuentan orgullosas sobre sus ritos, sobre el meek'bir, ritual por el que a un pequeño se le da nombre y con ello es reconocido en su comunidad; se refieren a sus compañeros que van a "las casas de piedra”, los antiguos templos del periodo prehispánico, y conocen cómo hablar con los dioses, les saben cantar a Ik Chan Yum, Nuestro Pequeño Señor, a $A h K^{\prime} a$ bilam, a los Yumtzil; también se comunican con los Wayantek para que no los espanten y temen a Kisin. Pero igual relatan con tristeza cómo, con la llegada de los evangelizadores y de la nueva religión, entierran a sus dioses. Expresan con gran angustia, el terror que les inspira la llegada de "otros" a la selva, presagio del fin de! mundo.

La lectura del libro provoca un sentimiento verdaderamente sobrecogedor, más aún para aquellas personas que no hemos convivido con estas comunidades. Es difícil imaginar una vida tan llena de escollos como la de las mujeres lacandonas que, sin embargo, soportan con gran estoicismo y resignación fatídica. Conmueve leer uno a uno los relatos en los que encontramos jóvenes, aun niñas, violadas por chicleros, padres que venden a sus hijas a cambio de una caja de municiones, alejándolas de la comunidad y luego rechazadas por la misma por tener hijos de dzules. La supremacía y el dominio masculino queda patente en cada uno de los actos, el padre o en su ausencia los hombres de la comunidad, deciden con quién casar a las mujeres, chiquillas, aún púberes, dadas en matrimonio a hombres maduros; los maridos golpean a sus esposas hasta fracturarles los huesos, pues ellas forman parte de las posesiones de los hombres, al igual que lo es el machete o la escopeta. Las mujeres son abandonadas con sus hijos sin necesidad de ningún pretexto, en una Estudios de Cultura Maya. Vol. XXII, 2002

Instituto de Investigaciones Filológicas/

Centro de Estudios Mayas, UNAM

ISSN 0185-2574 realidad en donde se precisa el trabajo masculino y femenino para sobrevivir. Sin embargo, aquellas viudas, abandonadas, huérfanas de padre, demuestran gran fuerza y sobreponiéndose a su destino trabajan en el campo al igual que los varones, cosechando su milpa, a la par que cuidan su hogar y a los pequeños, dándonos una lección de sobrevivencia, un ejemplo de carácter y de lucha ante el infortunio.

No deja de asombrar a los ojos de un occidental las hermanas que comparten a un marido, las más de las veces no sólo sin mostrar celos, sino todo lo contrario, manifestando una fuerte solidaridad femenina, una lealtad entre mujeres que las protege de una existencia tan penosa. Muy lejos están las lacandonas de llevar una vida paradisiaca y a pesar de ello se declaran felices al tener un marido que construya su vivienda, coseche una milpa, y provea de caza, pero que no las golpee; agradecerán tener hijos a los que se les transmitan sus costumbres para mantener una liga con su pasado, pues son las mujeres las conservadoras de la identidad étnica y, claro, agradecerán algún lujo: un corte para confeccionarse una prenda de vestir, tal vez unas chanclas, y porqué no, un poco de jabón. A cambio ellas harán la comida, hilarán las telas, cuidarán a los hijos, llevarán el agua, lavarán la ropa, molerán el maíz y harán las tortillas; recolectarán fruta, saldrán a pescar, cosecharán frijoles, y ayudarán al marido en el trabajo de la milpa cuando éste lo requiera.

Marion, a través de diversos testimonios, que sólo pudo obtener mostrando siempre una gran discreción y paciencia para ganarse el respeto y confianza de los indígenas, nos presenta un mundo femenino que lucha por sobrevivir, por conservar sus tradiciones, por convivir en armonía con su medio ambiente, por defenderse y protegerse de las agresiones masculinas. Las indígenas son las oprimidas de los oprimidos; son las que más resienten y temen el enfrentamiento con otras culturas que penetran en su refugio selvático. La certera elección de la autora de las historias de vida, permite captar los cambios sucedidos dentro de la comunidad lacandona en los últimos años; gracias a dichos textos compartimos como ella, momentos de la 
vida cotidiana de estas mujeres, pero en la comodidad de nuestras ciudades, de nuestro hogar. Conforme avanzamos en la lectura de este libro nos compenetramos con los personajes y aprendemos, como Marion, a quererlos, de tal forma que al terminar los textos, y no encontrar más a Na'k'in, a Es, a Chana'k'in o a la pequeña Cuti, queda una sensación de vacío.

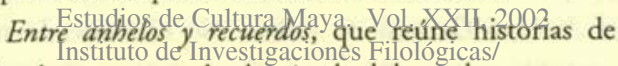
vida, decesperanzas de alegría de dolany de muerte, es un ejemplo más del compromiso de la autora con los lacandones. Refleja, no sólo los conocimientos y la estricta y novedosa metodología de la antropóloga, sino también su compenetración, interés, comprensión, respeto y amistad que han surgido a lo largo de los años, durante sus largas estadías en la selva lacandona, por ese otro mundo que lucha por sobrevivir, por adaptarse a los cambios pero sin perder su identidad. 